\title{
Investigation of the efficacy of aminoguanidine in an experimental rat model with isolated bilateral pulmonary contusion due to blunt thoracic trauma
}

\author{
(1) Dilek Atik, ${ }^{1}$ (1) Derya Balci Koroglu, ${ }^{2}$ (i) Bahadir Taslidere ${ }^{3}$ \\ ${ }^{1}$ Department of Emergency Medicine, Kanuni Sultan Suleyman Hospital, Istanbul, Turkey \\ 2Department of Thoracic Surgery, Diskapi Training and Research Hospital, Ankara, Turkey \\ ${ }^{3}$ Department of Emergency Medicine, Bezmialem University Faculty of Medicine, Istanbul, Turkey
}

\begin{abstract}
OBJECTIVE: In severe thoracic trauma, the pulmonary contusions that are almost inevitable and associated with high morbidity and mortality. In this study, we aimed to evaluate the antioxidant activity of aminoguanidine in pulmonary contusion.

METHODS: Sixty-three Sprague-male rats were used in this study. Sham and aminoguanidine groups were exposed to isolated blunt thoracic trauma with a force of 1,512 joules. Aminoguanidine was administered intraperitoneally at a dose of $100 \mathrm{mg} / \mathrm{kg}$ three hours before the trauma and on the 1. and 2. day after the trauma. The contusion group was exposed to blunt thoracic trauma only. In all groups, arterial blood gas analysis and catalase and NO levels were reported on the $0^{\text {th }}, 1^{\text {st }}$, $2^{\text {nd }}$ and $3^{\text {rd }}$ days.

RESULTS: $\mathrm{PO}_{2}$ levels were higher in the sham group compared to the contusion group, without statistical significance. On the third day, $\mathrm{SaO}_{2}$ levels were higher in the AG group compared to the contusion group. $\mathrm{SaO}_{2}$ levels were comparable in the $\mathrm{AG}$ and sham groups on days 1,2 and 3. There was no difference between the $\mathrm{PaO}_{2}$ levels of the contusion and sham groups on the $2^{\text {nd }}$ and $3^{\text {rd }}$ days. There was no difference between the $\mathrm{PaO}_{2}$ levels of the $\mathrm{AG}$ and sham groups on the $1^{\text {st }}, 2^{\text {nd }}$ and $3^{\text {rd }}$ days. We found no difference between the $\mathrm{PaCO}_{2}$ levels of the contusion and sham groups on the 0-3 days. There was no difference between the $\mathrm{PaCO}_{2}$ levels of the $\mathrm{AG}$ and sham groups on the $1^{\text {st }}, 2^{\text {nd }}$ and $3^{\text {rd }}$ days. No difference was observed between the $\mathrm{PaCO}_{2}$ levels of the $\mathrm{AG}$ and contusion groups on the $1^{\text {st }}, 2^{\text {nd }}$ and $3^{\text {rd }}$ days. No significant difference was found between the NO levels of the sham and the contusion groups on day 0 . There was a significant difference between the sham and contusion groups on the $1^{\text {st }}, 2^{\text {nd }}$ and $3^{\text {rd }}$ days. There was no statistically significant difference between the catalase enzyme activities of the sham and AG groups.
\end{abstract}

CONCLUSION: In our study, we showed that the use of aminoguanidine did not significantly reduce the severity of pulmonary contusion and the inflammatory reaction induced by thoracic trauma in rats.

Keywords: Aminoguanidine; blunt thoracic trauma; catalase activity.

Cite this article as: Atik D, Balci Koroglu D, Taslidere B. Investigation of the efficacy of aminoguanidine in an experimental rat model with isolated bilateral pulmonary contusion due to blunt thoracic trauma. North Clin Istanb

A mong all trauma cases, chest trauma is the third most common after head and neck and extremity traumas, respectively. Chest trauma is the most common cause of death, especially in the first four decades of life.

It occurs due to traffic accidents, occupational accidents, falls and assaults, and constitutes $25 \%$ of trauma-related deaths [1]. The mortality rate of isolated chest trauma is $5.5 \%$, but if an additional organ system is injured, this

Received: April 09, 2019 Accepted: April 25, 2020 Online: August 11, 2020

Correspondence: Dilek ATIK, MD. Kanuni Sultan Suleyman Hastanesi, Acil Servisi, Istanbul, Turkey.

Tel: +905059445091 e-mail: dr.dlekgok82@hotmail.com

(c) Copyright 2020 by Istanbul Provincial Directorate of Health - Available online at www.northclinist.com 
TABLE 1. SatO ${ }_{2}, \mathrm{PaO}_{2}$ (blood gas) values between groups

\begin{tabular}{rcccc}
\multicolumn{1}{c}{ Day } & Sham & Contusion & Aminoguanidine & Aminoguanidine+contro \\
\hline $\mathrm{SatO}_{2}$ & & & & \\
0 & $94.85(91.0-96.6)$ & $65.03(31-90)$ & - & $90.51(84-96.6)$ \\
1 & $94.85(91.0-96.6)$ & $65(32-89.1)$ & $87.3(78.1-95)$ & $90.51(84-96.6)$ \\
2 & $94.85(91.0-96.6)$ & $77.27(64.3-86.1)$ & $81.48(75-86.4)$ & $90.51(84-96.6)$ \\
3 & $94.85(91.0-96.6)$ & $80.7(71.8-83)$ & $89.78(84.5-96.8)$ & $90.51(84-96.6)$ \\
$\mathrm{PaO}_{2}$ & & & & \\
0 & $81.98(64.7-94.1)$ & $47.03(27.3-70.2)$ & - & $75.17(53.7-85.7)$ \\
1 & $81.98(64.7-94.1)$ & $48.03(27.3-71.2)$ & $79.3(57-104)$ & $75.17(53.7-85.7)$ \\
2 & $81.98(64.7-94.1)$ & $67.17(57.3-78.7)$ & $61.94(55.2-77.4)$ & $75.17(53.7-85.7)$ \\
3 & $81.98(64.7-94.1)$ & $65.25(52-87)$ & $72.88(58-92.4)$ & $75.17(53.7-85.7)$
\end{tabular}

rate rises to $12-15 \%$, and if there is multiple organ injury, it increases up to 30-35\% [2]. Pulmonary contusion is defined as trauma-induced alveolocapillary damage associated with overstretching or even rupture of alveoli, separation of alveoli from bronchioles, intra-alveolar bleeding, and interstitial edema. Pulmonary contusion occurring in $30-75 \%$ of major thoracic trauma cases is a severe injury with high mortality and morbidity. It may be associated with various severe conditions ranging from simple dyspnea to respiratory failure requiring mechanical ventilation. Acute respiratory distress syndrome and multiple organ dysfunction may develop depending on the extent of the contusion [3] because the mortality rate of $11 \%$ in an isolated severe contusion increases to $22 \%$ in the presence of additional injuries. The incidence of ARDS is $17 \%$ in isolated contusions, but up to $78 \%$ with additional injuries. Pulmonary embolism and pneumonia are important factors that increase mortality caused by pulmonary contusion. Pulmonary contusion involves an inflammatory process that occurs due to mechanical damage, with a mechanism that is not fully known. Inflammatory response, and therefore, neutrophils, which are the major factors in endothelial/epithelial damage, are the most critical factors determining prognosis [4]. Therefore, it is an issue open to the development of novel treatment methods through further studies. In trauma-induced lung injury, gas exchange in bronchioles and alveoli is impaired, resulting in hypoxemia and hypercarbia. Leukocyte infiltration, production of inflammatory mediators, and free oxygen radicals have a significant role in the pathogenesis of this chain of events. Free oxygen radicals may cause oxidative damage through lipid peroxidation, thereby disrupting the integrity of the cell membrane and increasing the permeability of the cells. The resulting hypoxia and hypovolemia may cause ischemia at the cellular level, resulting in necrosis. However, the formation of free oxygen radicals during reperfusion usually aggravates the tissue damage. Therefore, it is necessary to reduce the harmful effects of free radicals in patients with pulmonary contusion. In a healthy organism, the balance between the formation of free radicals and their elimination by antioxidants is called the oxidative balance. In animal models, antioxidant therapy has been shown to be beneficial against lung injury. Nitric oxide, which is effective in the inflammatory process, is synthesized from the amino acid L-arginine by the effects of nitric oxide synthetase. Nitric oxide (NO) synthesized from endothelium leads to pulmonary vasodilatation, reducing shunting in well-ventilated lung regions, increasing oxygenation and decreasing pulmonary edema [5]. Expression of NOS in acute lung injury and inflammatory lesions of the colon has been shown to lead to overproduction of NO, resulting in the production of superoxide and peroxynitrite. The aminoguanidine, a nucleophilic hydralazine derivative from the biguanide group, inhibits nitric oxide synthase via its hydrazine group. It acts as an antioxidant to prevent the formation of reactive oxygen compounds and lipid peroxidation in cells and tissues, thus performing as a kind of free radical scavenger [6-7]. Catalase is an antioxidant enzyme found in peroxisomes within the cell. It catalyzes the reaction that converts hydrogen peroxide to water and oxygen. It oxidizes organic compounds, such as phenol, formaldehyde and alcohol, using $\mathrm{H}_{2} \mathrm{O}_{2}$, which is formed by the oxidation of glucose 
molecules during metabolism, especially in liver and kidney cells. Thus, toxic substances from the bloodstream are detoxified. Catalase exhibits its reducing activity on small molecules, such as $\mathrm{H}_{2} \mathrm{O}_{2}$, methyl and ethyl hydroperoxides. It has no effect on lipid hydroperoxides, which have a large molecular structure [8]. One way of reducing tissue damage associated with $\mathrm{NO}$ and peroxynitrite is to inhibit the overproduction of NO by a specific inhibitor of iNOS, such as AG. The involvement of oxidative stress and inflammatory process in tissue damage induced us to investigate the effects of aminoguanidine on pulmonary contusion in an experimental rat model with isolated bilateral lung contusion due to blunt thoracic trauma. In the light of this information, our study aimed to reduce the endothelial/epithelial damage in lung contusion by suppressing the inflammatory mechanism and to investigate the effects of this reduction on mortality and morbidity.

\section{MATERIALS AND METHODS}

This study was approved by the Animal Experiments Ethics Committee (14.05.2011) of the Hospital (2010/19) and used 63 Sprague Dawley rats from Experimental Animal Production Laboratory. Before the experiment, the rats were kept in wire cages for 12 hours at night and 12 hours at daytime, in circadian rhythm at an ambient temperature of 20 to $26^{\circ} \mathrm{C}$ for 10 days. Twelve hours before the experiment, feeding was stopped, except for water. All rats were cared for in accordance with the principles of Care of Experimental Animals formed by the National Society for Medical Research (NSMR) and with the Guide for the Care and Use of Laboratory Animals prepared by the Institute of Laboratory Animal Resources and published by the National Institute of Health. The groups were formed by randomly assigning seven rats to each group (Table 1). Group 1 (Sham) $(n=7)$, subjected to blunt thoracic trauma and not given aminoguanidine. Group 2 (Control) $(n=7)$, not subjected to blunt thoracic trauma but given aminoguanidine. Group 3 (Contusion) $(n=28)$, subjected to pulmonary contusion by blunt thoracic trauma and given saline via the intraperitoneal route. Four subgroups were created for the $0^{\text {th }}, 1^{\text {st }}, 2^{\text {nd }}$ and $3^{\text {rd }}$ days. Group 4 (Aminoguanidine) $(n=21)$, subjected to pulmonary contusion by blunt thoracic trauma and given aminoguanidine. A total of three subgroups were created for the $1^{\text {st }}, 2^{\text {nd }}$ and $3^{\text {rd }}$ days. In the groups given aminoguanidine, the administration was performed by
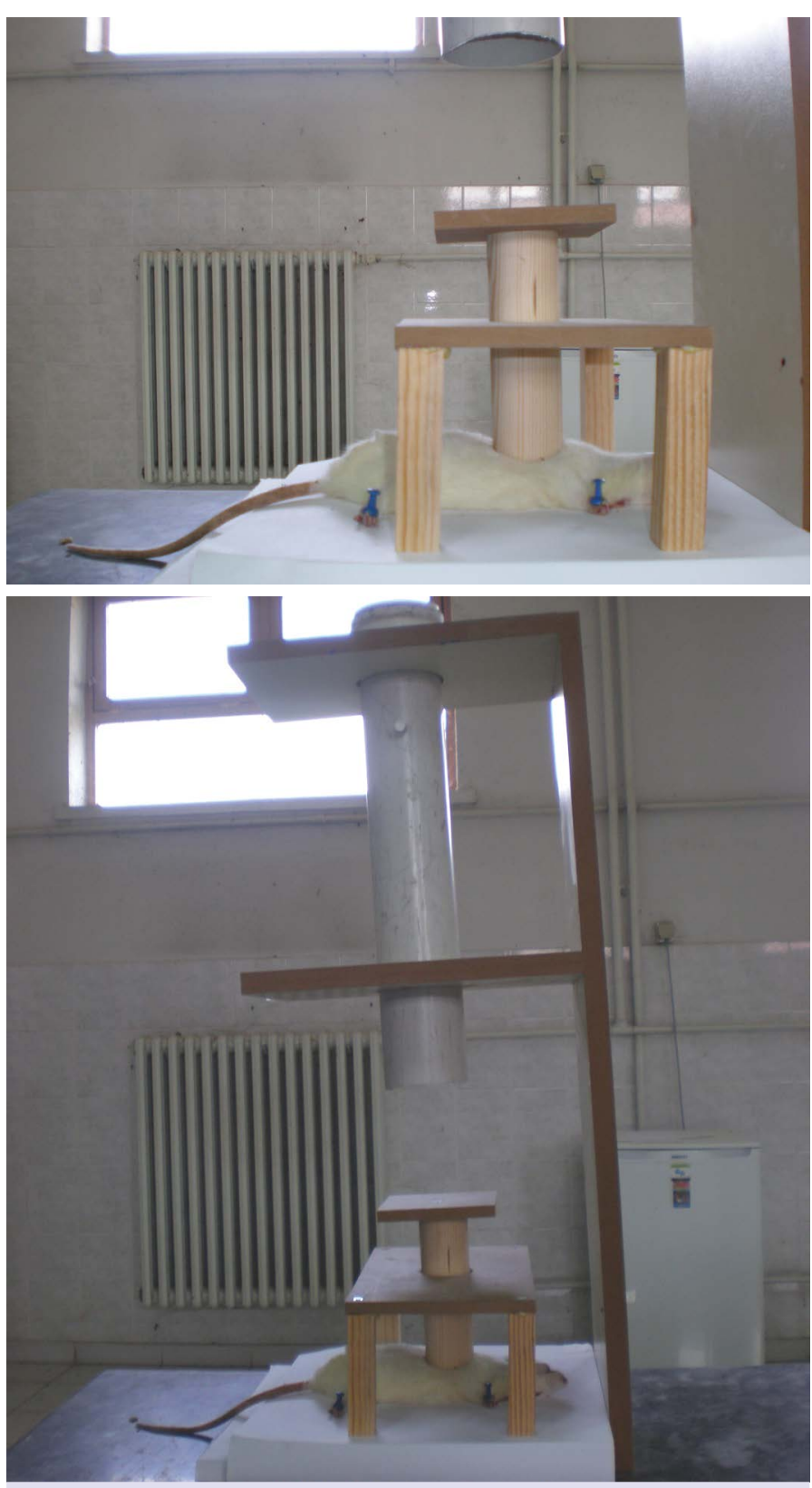

FIGURE 1. Mechanism used for blunt thoracic trauma.

an intraperitoneal route at a dose of $100 \mathrm{mg} / \mathrm{kg} 3$ hours before the trauma. In the control and aminoguanidine groups, $100 \mathrm{mg} / \mathrm{kg}$ dose of aminoguanidine was continued on the $2^{\text {nd }}$ and $3^{\text {rd }}$ days. Rats that were fasted 12 hours before the procedure were anesthetized with $100 \mathrm{mg} / \mathrm{kg}$ xylazine and $10 \mathrm{mg} / \mathrm{kg}$ ketamine. The lexon platform was used to create pulmonary contusion through the effects transmitted to the thoracic wall by saving the sternum and heart. The rats were exposed to blunt thoracic trauma with a force of 1,512 joules, except for sham and control groups [9] (Fig. 1). After the trauma, $2 \mathrm{cc}$ blood samples were taken from the abdom- 


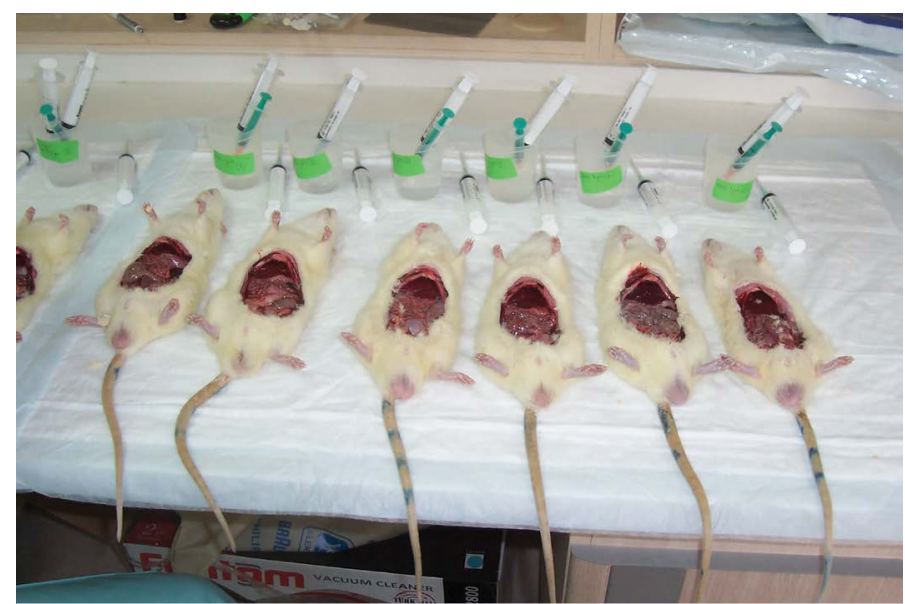

FIGURE 2. System for collection of blood samples for serial blood gas and other studies in rats which were under anesthesia and underwent trauma.

inal aorta of seven rats in contusion and sham groups under anesthesia. In these blood samples, it was aimed to determine the levels of $\mathrm{PaO}_{2}, \mathrm{SaO}_{2}$ and $\mathrm{PCO}_{2}$, and catalase and malondialdehyde among oxidative stress parameters. On day 1 , the sham group, $0^{\text {th }}$ and $1^{\text {st }}$-day subgroups of the contusion group and $1^{\text {st }}$-day subgroup of the AG group were sacrificed. There are four rats died on the $1^{\text {st }}, 2^{\text {nd }}$ and $3^{\text {rd }}$ days. On day 2 , the administration of the drug continued in the remaining rats (not sacrificed). On the $2^{\text {nd }}$ day, the $2^{\text {nd }}$-day sub-groups of the contusion group and AG groups were subjected to the procedures performed in the sham group and the $1^{\text {st }}$-day subgroup of the AG group. On the $3^{\text {rd }}$ day, the $3^{\text {rd }}$-day sub-groups of the contusion group and AG groups were subjected to the procedures performed in the sham group and the $1^{\text {st }}$-day subgroup of the AG group. The exploration revealed that the causes of death in the rats were pneumothorax, hemothorax, and cardiac tamponade (Fig. 2).

Blood samples were taken into EDTA-K3 anticoagulant tubes and centrifuged at $3000 \mathrm{rpm}$ for 10 minutes. After centrifugation, the supernatant plasma was transferred to Eppendorf tubes and stored at $-80^{\circ} \mathrm{C}$ until analysis. Plasma levels of $\mathrm{NO}$ and catalase were studied. You can follow the experimental flow chart in the generated scheme (Fig. 3).

\section{Statistical Analysis}

Data were recorded in pre-prepared forms. The recorded data were numbered and transferred to the computer. Statistical analysis was performed using SPSS for Win-

\section{A total of 63 Sprague Dawley rats were used}

Twelve hours before the experiment, feeding was stopped, except for water

Rats which were fasted 12 hours prior to the procedure were anesthetized with $100 \mathrm{mg} / \mathrm{kg}$ xylazine and $10 \mathrm{mg} / \mathrm{kg}$ ketamine

Rats are fixed to the Lexon Platform, a contusion mechanism

The rats were to exposed to blunt thoracic trauma with a force of 1.512 joules, except for sham and control groups

The groups were formed by randomly assigning 7 rats to each group

2 cc blodd samples were taken from contusion and sham groups in these blood samples, it was aimed to determine the levels of $\mathrm{PaO}_{2}$ and $\mathrm{PCO}_{2}$, and of catalase and malondialdehyde among oxidative stress parameters

Group 1: Not subjected to blunt thoracic and not given aminoguanidine

Group 2: Not subjected to blunt thoracic trauma but given aminoguanidine

Group 3: Subjected to pulmonary contusion by blunt thoracic trauma and given saline via intraperitoneal route

Group 4: Subjected to pulmonary contusion by blunt thoracic trauma and given aminoguanidine

In the groups given aminoguanidine, the administration was performed by intraperitoneal route at a dose of $100 \mathrm{mg} / \mathrm{kg} 3$ hours before the trauma. In the control and aminoguanidine groups, 100 $\mathrm{mg} / \mathrm{kg}$ dose of aminoguanidine was continued on the $2^{\text {nd }}$ and $3^{\text {rd }}$ days

FIGURE 3. Experimental flow-chart.

dows version 15.0. Median, minimum and maximum values of the groups were calculated. Intergroup comparison was performed by Kruskal-Wallis variance analysis. Chi-Square Test was used for intergroup comparison of categorical data. A p-value of $<0.05$ was considered significant.

\section{RESULTS}

Evaluation of the $\mathrm{SaO}_{2}$ and $\mathrm{PaO}_{2}$ levels showed no difference between the Sham and AG groups on the $1^{\text {st }}$, $2^{\text {nd }}$ and $3^{\text {rd }}$ days, whereas a significant difference be- 
TABLE 2. Nitric oxide values between groups

\begin{tabular}{lcccc} 
Day & Sham & Contusion & Aminoguanidine+contusion & Aminoguanidine+control \\
\hline 0. & $3.7(1.68-6.76)$ & $8.58(1.72-20.05)$ & - & $3.06(0.35-4.6)$ \\
1. & $3.7(1.68-6.76)$ & $10.3(4.64-16.6)$ & $5.25(1.6-10.68)$ & $3.06(0.35-4.6)$ \\
2. & $3.7(1.68-6.76)$ & $9.77(2.6-11.6)$ & $7.26(4.38-9.54)$ & $3.06(0.35-4.6)$ \\
3. & $3.7(1.68-6.76)$ & $9.78(2.6-13.5)$ & $4.32(3.37-5.5)$ & $3.06(0.35-4.6)$
\end{tabular}

tween sham and contusion groups on the $2^{\text {nd }}$ and $3^{\text {rd }}$ days $(p<0.05)$. There was no significant difference in the $\mathrm{SaO}_{2}$ levels of $\mathrm{AG}$ and contusion groups on the $1^{\text {st }}$ and $2^{\text {nd }}$ days $(p>0.05)$. The $\mathrm{SaO}_{2}$ levels of the $\mathrm{AG}$ group on day 3 were significantly different compared to the contusion group $(p<0.05)$. There was no statistically significant difference between $\mathrm{paO}_{2}$ levels of $\mathrm{AG}$ and contusion groups. No significant difference was found between the groups Sham and $\mathrm{AG}$ in terms of $\mathrm{PaCO}_{2}$ levels on the $1^{\text {st }}, 2^{\text {nd }}$ and $3^{\text {rd }}$ days $(p>0.05)$. No significant difference was found between the sham and contusion groups in terms of $\mathrm{PaCO}_{2}$ levels on the $0^{\text {th }}$ and $1^{\text {st }}$ days. Significant differences were found in $\mathrm{paCO}_{2}$ levels between the sham and contusion groups on the $2^{\text {nd }}$ and $3^{\text {rd }}$ days $(p<0.05)$ (Table 1$)$. No significant difference was found between the $A G$ and the contusion groups concerning $\mathrm{paCO}_{2}$ levels $(\mathrm{p}=0.05)$ (Table 2). No significant difference was found between the NO levels of the sham and the contusion groups on day 0 . There was a significant difference between the sham and contusion groups on the $1^{\text {st }}, 2^{\text {nd }}$ and $3^{\text {rd }}$ days $(p<0.05)$ (Table 2$)$. We found a significant difference between the groups Sham and AG on the $1^{\text {st }}$ and $2^{\text {nd }}$ days, with no significant difference on the $3^{\text {rd }}$ day $(p>0.05)$. No significant difference was found between the Sham and AG control groups on the $1^{\text {st }}, 2^{\text {nd }}$ and $3^{\text {rd }}$ days $(p>0.05)$. Comparison of AG and contusion groups showed a decrease in NO levels in the AG group, with no statistically significant difference $(p>0.05)$. No significant difference was found between the AG and AG control groups concerning NO levels ( $p>0.05$ ) (Fig. 4). No significant difference was found between the catalase enzyme activities of sham and contusion groups on all days ( $p>0.05)$. There was no statistically significant difference between Sham and AG groups ( $p>0.05)$. No significant difference was found between Sham and AG control groups ( $p>0.05)$. The comparison of AG and contusion groups showed a significant increase in catalase enzyme activi-

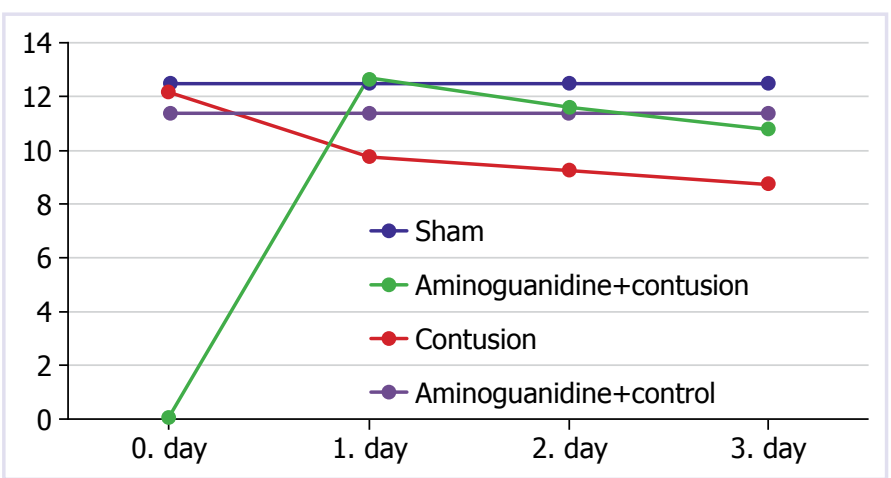

FIGURE 4. Catalase values between groups.

ty on days 1 and 2 in the AG group $(p<0.05)$, without significant difference on day $3(p>0.05)$. No significant difference was found between the AG and AG control groups in terms of catalase enzyme activity $(p>0.05)$.

\section{DISCUSSION}

Trauma is one of the most common causes of death in the young adult population. Chest traumas, which usually occur as a result of traffic accidents, occupational accidents, assaults and falls, are the third most common after head and limb traumas [10]. Pulmonary contusion can be seen in approximately $50 \%$ of the patients with chest trauma, which is one of the most important factors that increase mortality by adversely affecting the clinical course. It is important to investigate the preventable causes of death to reduce mortality from chest trauma seen predominantly in young adults. Secondary damage following a trauma causing pulmonary contusion involves oxidative stress, lipid peroxidation, and inflammatory response $[11,12]$. Oxidative stress is the deterioration of the physiological balance between the formation of free radicals and their elimination by antioxidants. Lipid peroxidation is the process of degradation of polyunsaturated fatty acids by oxidation. 
After this process, the resulting products may adversely affect the surrounding tissues. The effects of lipid peroxidation on the cell membrane are irreversible [13]. The presence of superoxide radicals (SORs) in the environment may lead to the synthesis of $\mathrm{NO}$ and peroxynitrite and triggers lipid peroxidation. These released SORs may cause oxidative damage through lipid peroxidation $[14,15]$. Aminoguanidine is a compound that inhibits selectively and competitively inducible nitric oxide synthase and thereby causes reduced nitric oxide formation. This is an effective antioxidant and free radical scavenger. It prevents the formation of lipid peroxidation in cells and tissues [16]. There are studies that have proven that aminoguanidine reduces both the inflammatory response and the degree of pulmonary injury. In studies, it was emphasized that aminoguanidine alone is not sufficient and the efficacy of combined treatments is more $[17,18]$. In a study, Soy et al. [19] showed that initiation of aminoguanidine treatment $(100 \mathrm{mg} / \mathrm{kg})$ immediately after the trauma prevented both nitric oxide production and lipid peroxidation and improved the functional status of animals. The administration of systemic antioxidant agents in intensive care patients with mechanical ventilator support reduced the plasma levels of lipid peroxidation products and the amount of mucus in the respiratory tract, resulting in better clinical results. In the present study, NO levels in the contusion group were significantly higher than the sham group. In addition, NO levels were lower in the aminoguanidine group compared to the contusion group. These elevated levels were attributed to trauma-induced alveolar-capillary damage and subsequent ventilation/perfusion mismatch. No statistically significant difference was found between NO levels of aminoguanidine and contusion groups. In addition, there was no significant difference between NO levels of the sham and aminoguanidine control groups. In our study, it was found that CAT enzyme levels increased significantly in the contusion group compared to the Sham group. No significant difference was found between the CAT enzyme activities of the contusion and AG groups ( $p>0.05)$. In addition, there was no significant difference between the CAT enzyme activities of the sham and AG control groups. The data obtained in our study were consistent with the literature and it was shown that aminoguanidine at a dose of $100 \mathrm{mg} / \mathrm{kg}$ might have protective effects against pulmonary damage mechanisms. We believe that it may be useful to carry out further studies with different doses to reveal the maximum efficacy of AG [20].

\section{Conclusion}

In our study, we observed that the use of aminoguanidine in rats exposed to isolated pulmonary contusion by blunt trauma reduces the severity of pulmonary contusion and minimizes the inflammatory reaction.

Ethics Committee Approval: The Diskapi Training and Research Hospital Animal Experiments Ethics Committee granted approval for this study (date: 09.05.2011, number: 23).

Conflict of Interest: No conflict of interest was declared by the authors.

Financial Disclosure: This study was supported by a project (09.05.2011-23) from the project is supported by Diskapi education and research hospital. Ankara, Turkey.

Authorship Contributions: Concept - DA, DBK; Design - DA, DBK; Supervision - DA, BT; Fundings - DA, DBK; Materials - DA, DBK; Data collection and/or processing - DA, BT; Analysis and/or interpretation - DA, DBK; Literature review - DA, BT; Writing - DA; Critical review - DA.

\section{REFERENCES}

1. Byun CS, Park IH, Oh JH, Bae KS, Lee KH, Lee E. Epidemiology of trauma patients and analysis of 268 mortality cases: trends of a single center in Korea. Yonsei Med J 2015;56:220-6.

2. Pehlivanlar Küçük M, Küçük AO, Aksoy İ, Aydın D, Ülger F. Prognostic evaluation of cases with thoracic trauma admitted to the intensive care unit: 10-year clinical outcomes. Ulus Travma Acil Cerrahi Derg 2019;25:46-54

3. Alisha C, Gajanan G, Jyothi H. Risk Factors Affecting the Prognosis in Patients with Pulmonary Contusion Following Chest Trauma. J Clin Diagn Res 2015;9:OC17-9.

4. Rendeki S, Molnar TF. Pulmonary contusion. J Thorac Dis 2019;11:S141-51.

5. Rus A, Peinado MA, Castro L, Del Moral ML. Lung eNOS and iNOS are reoxygenation time-dependent upregulated after acute hypoxia. Anat Rec (Hoboken) 2010;293:1089-98.

6. Kubes P, McCafferty DM. Nitric oxide and intestinal inflammation. Am J Med 2000;109:150-8.

7. Nieves C Jr, Langkamp-Henken B. Arginine and immunity: a unique perspective. Biomed Pharmacother 2002;56:471-82.

8. Topcu K, Kırıc1 DÖ, Evcil MS. Catalase activity in healthy and inflamed pulp tissues of permanent teeth in young people. Niger J Clin Pract 2016;19:600-2.

9. Guven B, Gokce M, Saydam O, Can M, Bektas S, Yurtlu S. Effect of ghrelin on inflammatory response in lung contusion. Kaohsiung J Med Sci 2013;29:69-74.

10. Tovar JA, Vazquez JJ. Management of chest trauma in children. Paediatr Respir Rev 2013;14:86-91.

11. Tignanelli CJ, Hemmila MR, Rogers MAM, Raghavendran K. Nationwide cohort study of independent risk factors for acute respiratory distress syndrome after trauma. Trauma Surg Acute Care Open 2019;4:e000249.

12. Durham RM, Moran JJ, Mazuski JE, Shapiro MJ, Baue AE, Flint LM. Multiple organ failure in trauma patients. J Trauma 2003;55:608-16. 
13. Akkuş I, Gültekin F, Aköz M, Cağlayan O, Bahçaci S, Can UG, et al. Effect of moderate alcohol intake on lipid peroxidation in plasma, erythrocyte and leukocyte and on some antioxidant enzymes. Clin Chim Acta 1997;266:141-7.

14. Bayir H, Marion DW, Puccio AM, Wisniewski SR, Janesko KL, Clark $\mathrm{RS}$, et al. Marked gender effect on lipid peroxidation after severe traumatic brain injury in adult patients. J Neurotrauma 2004;21:1-8.

15. Scholpp J, Schubert JK, Miekisch W, Noeldge-Schomburg GF. Lipid peroxidation early after brain injury. J Neurotrauma 2004;21:667-77.

16. Al Drees A, Salah Khalil M, Soliman M. Histological and Immunohistochemical Basis of the Effect of Aminoguanidine on Renal Changes Associated with Hemorrhagic Shock in a Rat Model. Acta Histochem Cytochem 2017;50:11-9.
17. Giri SN, Biring I, Nguyen T, Wang Q, Hyde DM. Abrogation of bleomycin-induced lung fibrosis by nitric oxide synthase inhibitor, aminoguanidine in mice. Nitric Oxide 2002;7:109-18.

18. Duran L, Guzel A, Akdemir HU, Demir F, Karadeniz C, Alacam H, et al. Cardioprotective effect of aminoguanidine in combination with steroid therapy after blunt chest trauma. Bratisl Lek Listy 2014;115:53843.

19. Jang AS, Choi IS, Lee S, Seo JP, Yang SW, Park KO, et al. Nitric oxide metabolites in induced sputum: a marker of airway inflammation in asthmatic subjects. Clin Exp Allergy 1999;29:1136-42.

20. Raghavendran K, Davidson BA, Helinski JD, Marschke CJ, Manderscheid P, Woytash JA, et al. A rat model for isolated bilateral lung contusion from blunt chest trauma. Anesth Analg 2005;101:1482-9. 